\title{
Design of Crawler Chassis Intelligent Leveling Device
}

\section{Tingyv Wang ${ }^{1, a}$, Tengfei $W^{1, b}$, Xiaorong $L v^{1, c^{*}}$ and Yan Huang ${ }^{1, d}$}

${ }^{1}$ college of machinery and electronics, Sichuan Agricultural University, Ya'an, Sichuan, China

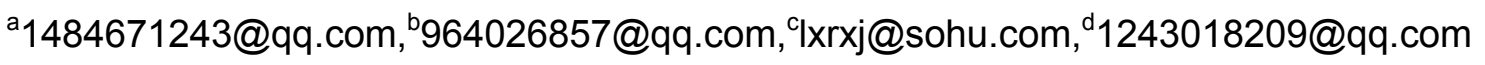

Keywords: Leveling device; Intelligent; Design; Hillside

\begin{abstract}
A kind of leveling device of intelligent chassis is designed thus vehicle driving platform can be maintained at level state constantly, directing at problems that drive platform cannot automatically remain level, and even overthrow accident of vehicles occurs when small-size hillside operational vehicle travels along slope, and leveling mechanism, mechanical structure design and intelligent control method are elaborated.
\end{abstract}

\section{Introduction}

Automatic leveling technology has been gradually widely applied[1-3]in aerial operation vehicle, military reconnaissance vehicle and landscaping equipment leading to efficient and safe equipment production. There is a large area of steep land in China, but function of most small-size operation vehicle is unitary[4-5]; especially at the time of driving or operation on steep slope, operation platform cannot automatically adjust spatial attitude, leading to lower stability of vehicles, psychological strain of drivers, low operation efficiency and production quality, and even overthrow accidents[6-8]. A kind of intelligent leveling device is designed and installed on chassis of hillside tractor to solve above problems, and functions of automatic leveling and intelligent adjustment of angle of operation platform are realized via control of single-chip.

\section{Structure and Operating Principle}

Overall Structure Design. Leveling device is composed of chassis, leveling board, triple-head cross-axle, screw rod slipway of stepping motor, control panel of single-chip, tilt sensor, etc, and leveling of leveling board is finished via vertical adjustment of screw rod slipway of stepping motor controlled by single-chip for operators. Structure diagram of leveling device design is shown in Fig. 1 .

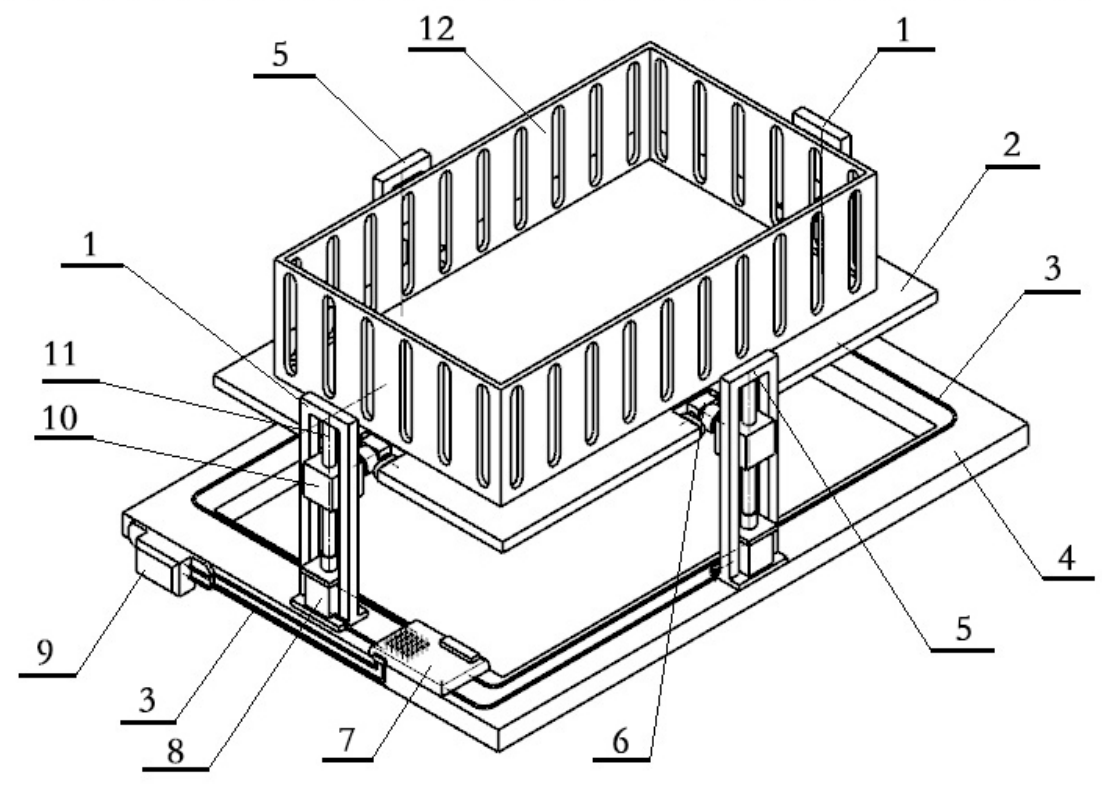

Figure 1. Structure diagram of leveling device 
1. Screw rod slipway of horizontal stepping motor 2. Leveling board 3. Circuit lead 4. Chassis 5. Screw rod slipway of vertical stepping motor 6. Triple-head cross-axle 7. Control board of single-chip 8. Stepping motor 9. Tilt sensor10. Slipway 11. Screw rod 12. Box of car body

Operating Principle. Chassis (4) and box of car body (12) are at tilted state when a tractor travels on vertical slope. Meanwhile included angle between car body and level is measured via tilt sensor and then measured dip signal is input into control board (7) of single-chip, and then signal is output from single-chip into four stepping motors (8), and screw rod slipway of vertical stepping motor begins to work, and one slipway ascends and the other descends according to tilt angle of slope, thus box (12) of car body of the tractor rotates bypassing cross-axle of triple heads, which makes box (12) of car body of the tractor maintain level.

Similarly, Chassis (4) and box of car body (12) are at tilted state when tractor travels on vertical slope. Meanwhile included angle between car body and level is measured via tilt sensor and then measured dip signal is input into control board (7) of single-chip, and then signal is output from single-chip into four stepping motors (8), and screw rod slipway of vertical stepping motor begins to work, and one slipway ascends and the other descends according to tilt angle of slope, thus box (12) of car body of the tractor rotates bypassing cross-axle of triple heads, which makes box (12) of car body of the tractor maintain level.

\section{Design of Main Working Parts.}

Design of main working parts of leveling device designed in this thesis is conducted via virtual three-dimension. A product design environment is provided by virtual design technology, and product design process is optimized, thus powerful support [9] is provided for $R \& D$ of new products. Design quality can be enhanced and design error as well as fabrication cost can be reduced via virtual design technology. Structural design [10] is conducted on parts via UGNX software on basis of above structural scheme of leveling device as well as main technological parameters, aiming at functional requirements and features of all component parts.

Design of Leveling Mechanism. Design of leveling board. A kind of leveling board structure is developed with good performances such as simple structure, little space occupied, flexible and reliable operation, etc, to ensure good leveling performance of leveling device, which is shown in Fig. 2.

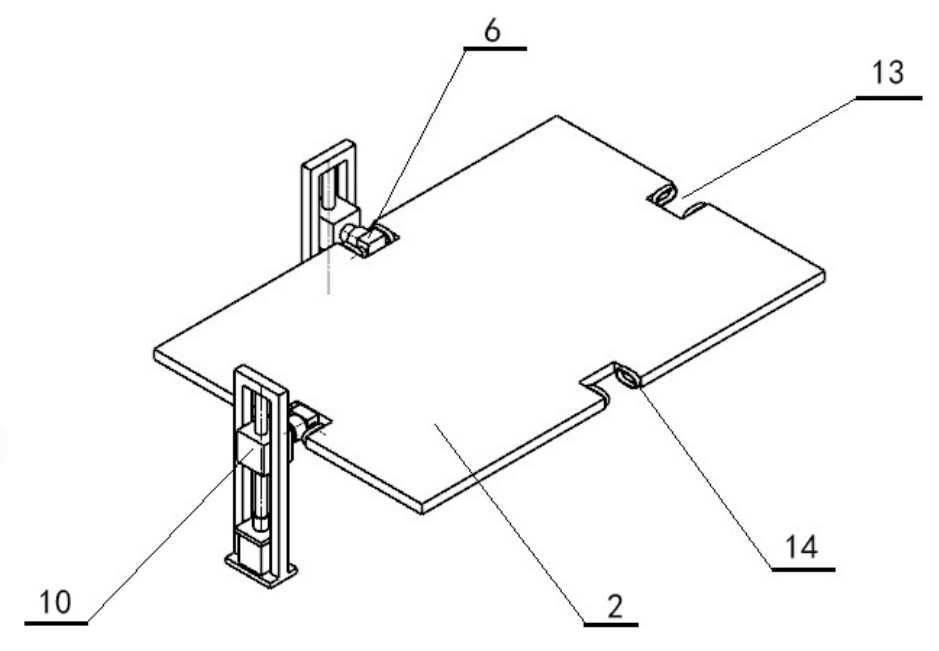

Figure 2. Structure of leveling board

2. Leveling board 6. Triple-head cross-axle 10. Slipway

13. Rectangular openings 14 . Keyway 
Rectangular openings (13) are placed in midpoints of four sides of leveling board (2), and two round-head keyways (14) are set on both sides of openings, and width of keyway is slightly over diameter of axle head of triple-head cross-axle, and round axle head of triple-head cross-axle (6) can rotate and slip in keyways. Box of car body is fastened to upper side of leveling board, and it can rotate with leveling board synchronously.

Design of triple-head cross-axle. Leveling board (2) and screw rod slipway of stepping motor are connected via triple-head cross-axle (6), which is shown in Figure 2. There are three axle-heads rotating independently on triple-head cross-axle, and its distribution way is similar to " $\mathrm{T}$ " shape, where two symmetrical axle-heads and round keyways on leveling board (2) are connected, and the two heads can rotate free in leveling board with respect to leveling board (2) and slip in short distance in keyways, while round sleeve on slipway (10) of screw rod slipway of stepping motor is connected to single-head in the middle part, which can rotate with respect to slipway free.

Structural Design of Hoisting Appliance of Stepping Motor. Hoisting appliance of stepping motor is composed of screw rod slipway of four stepping motors, which are divided into screw rod slipway (2) of vertical stepping motor and screw rod slipway (5) of horizontal stepping motors, respectively fastened to midpoints of chassis (4) vertically shown in Fig. 3 Slipway is in midpoint position of screw rod and midpoint of slipway is at the same line as circle center of round axle-head on single-head side of triple-head cross-axle when leveling is not started. There is round sleeve on slipway of screw rod slipway of stepping motor, and sleeve is fastened onto slipway, which is coordinated with single-head gap of triple-head cross-axle, and its axle-head can rotate with respect to slipway. Slipway can move vertically.

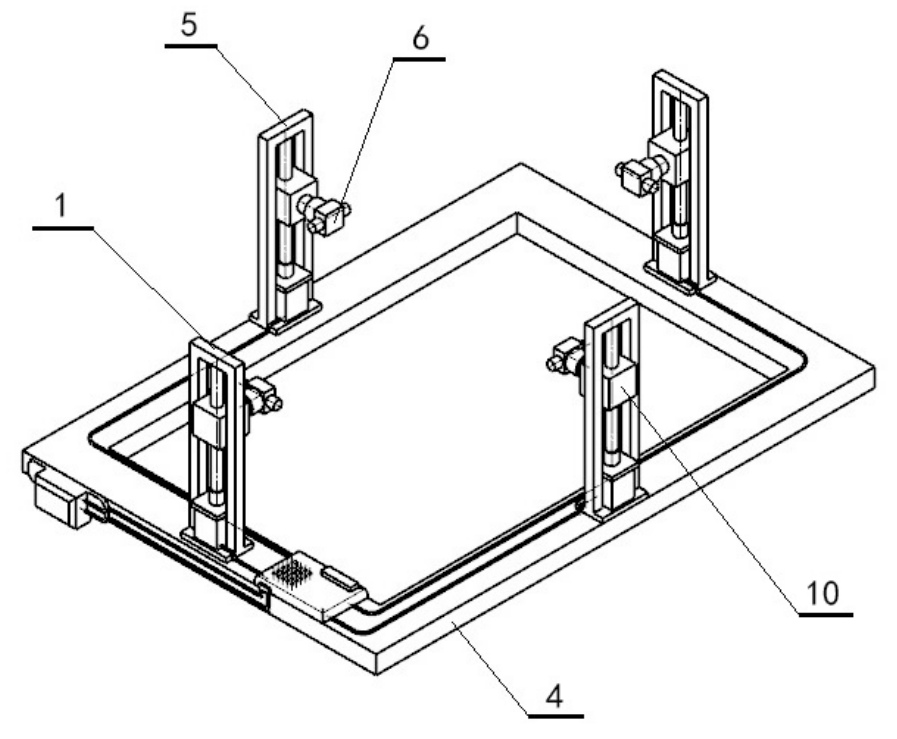

Figure 3. Hoisting appliance of stepping motor

2. Screw rod slipway of vertical stepping motor 4. Chassis 5. Screw rod slipway of horizontal stepping motor6. Triple-head cross-axle 10. Slipway

Form Design of Detection Device and Control Device. Detection device is composed of measuring transducers and connected to control device namely control board of single-chip via circuit lead. Signal will be sent to control board of single-chip when tilt of car body is detected by measuring transducers, then specific stepping motor will rotate upon receiving signal of control board for single chip, thus leveling board and box of car body will tilt, which leads to constant level of car body box when vehicle is on slope. 


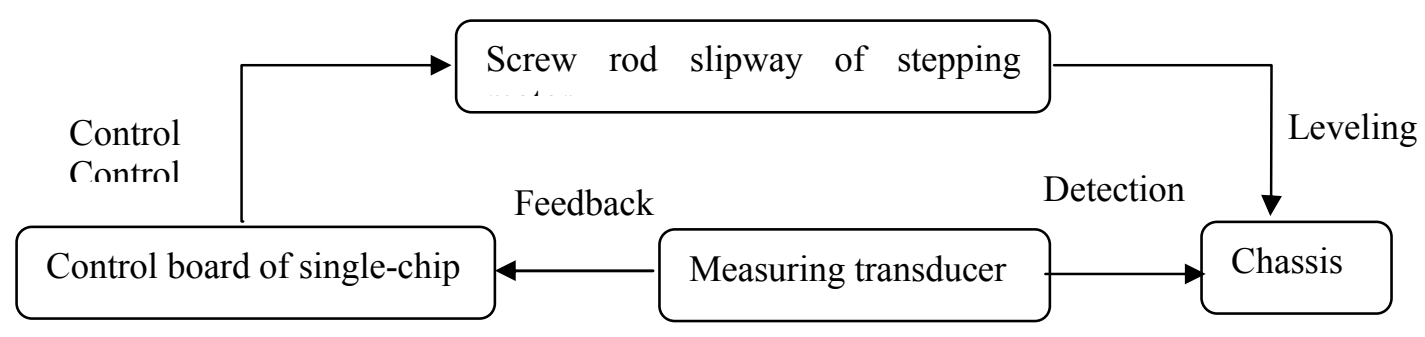

Figure 1. Schematic diagram of detection and control devices

\section{Summary}

Car body can be adjusted via intelligent control of single-chip for intelligent and automatic leveling device designed in this thesis. Restrict on hillside tractor due to factors such as irregular lot shape, big slope of hillside, etc can not only be overcome, but also intelligent degree of hillside tractor can be increased, thus labor intensity of farmers can be greatly alleviated via the fact that vehicle driving platform can be maintained at level state constantly in hillside environment.

\section{Acknowledgements}

Sichuan province leaders in academic and technical training project funding.

Correspondence Author: Lv Xiaorong, college of machinery and electronics, Sichuan agricultural university,ya'an,china,lxrxj@sohu.com.

\section{References}

[1] Sun Jianghong. A new automatic leveling platform structure and control system design [A]. Mechanical design and manufacturing, 2015,7.

[2] Hu Lian, Lin Chaoxing, Luo Xiwen, etc. Agricultural machinery automatic leveling control system design and test [J]. Journal of Agricultural Engineering, 2015,31 (8): 15-20.

[3] Xiao Chuang. Simulation study on vehicle stability control method [D]. Changsha: Hunan University,2007.

[4] Zhang Fang.Study on leveling control system of high precision platform [D].Hebei : North University of China, 2008.

[5] Tang Yu. Agricultural machinery driving seat automatic leveling system research [D]. Northwest A \& F University, 2010.

[6] Lin Jianming, mountain forestry track tractor chassis and its body leveling [J]. Forestry Machinery, 1987 (5): 19-22.

[7] Xie Weiguo, southern mountain afforestation machinery land preparation operation mode overview [J]. Anhui Agricultural Science Bulletin, 2011 (17): 159-160.

[8] Liu Kai, Yao Lihong, Zhang Qiang, et al. Design of automatic leveling system for small-scale agricultural vehicles [J]. Journal of Jiangsu Agricultural Sciences, 2013,41 (3): 363-366.

[9] Wu Qunbo, Zhang Linxiao, Xiao Tianyuan, Long Xinhai. Product innovation design in virtual product development environment [A]. China Mechanical Engineering, 2003, 14 (2): 116-119.

[10] Zhang Lihua, Lv Xiaorong. UG NX6.0 computer aided design and manufacturing practical tutorial [M]. Beijing: Peking University Press, 2009, 6. 